\title{
Design and implementation of Technology Service Platform of Industry Clusters in Engineering Machinery based on SOA
}

\author{
Qiufeng Wang ${ }^{1, a}$, Jie $\mathrm{Fu}^{2, \mathrm{~b}}$, Haiming Zhao ${ }^{3, \mathrm{c}}$ Xuanhua $\mathrm{Xu}^{4, \mathrm{~d}}$, \\ ${ }^{1}$ Central South University Library (new campus), Central South University, Changsha 410083, \\ China \\ ${ }^{2}$ School of Software, Central South University, Changsha 410075, China \\ ${ }^{3}$ College of Mechanical and Electrical Engineering, Central South University, Changsha 410083, \\ China \\ ${ }^{4}$ Business School, Central South University, Changsha 410083, China

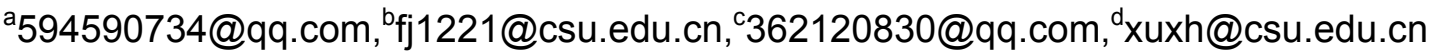

\begin{abstract}
Keywords: SOA, Service Platform, Industry Clusters in Engineering Machinery
\end{abstract}
\begin{abstract}
To solve the problem of "Information Island", namely, the condition when the data cannot be shared in the process of industry clustering, and wasted resources in Engineering Machinery industry clusters. An implementation method of technology service platform of industry cluster in engineering machinery based on SOA was proposed. This paper described the process of test application functionality, and established a BPEL model of test functionality. The platform was deployed to Oracle for testing the functionality. The results showed that the overall function of the platform is complete, response fast, high efficiency and provided a reference for related services completed.
\end{abstract}

\section{Introduction}

The machinery industry in China has been developing rapidly since the reform and opening up. The tendency of Industrial clustering in all parts of the country has been extremely obvious. At present, the Changsha area as the center, Zoomlion, Sany, Sunward and other enterprises as the core of the construction machinery industry cluster characteristics of Hunan positive development highlights the infinite vitality[1]. However, lots of problems in the development of industry clusters in engineering machinery emerge within recently years. For example, support services of industrial chain are deficient, collaboration between engineering machinery enterprises is weak. Large amounts of data from each enterprise can't be shared, which leads to islands of information, causing a huge waste of resource. Therefore, we need an integrated platform to provide the appropriate support services for various enterprises of mechanical engineering during the industry cluster. We can use development scheme of application integration which is based on SOA to solving these problems, especially for the communication in plurality of different technologies development and running on different platforms[2]. In this paper, we proposed a solution which was based on a service-oriented construction for technology service platform of industry clusters in engineering machinery. A platform was set up based on SOA, using the Web services technology. The platform is open, flexible and loosely coupled.

\section{SOA technology}

The concept of Service Oriented Architecture (SOA) was firstly devised in Gartner's 1996. At present, the core architecture that is based on Web Service is in common use. It is loosely coupled and highly multiplexed. We can use it to solve the loosely coupled relationship between the service requester and service provider in distributed system architecture. SOA requires service requesters, service providers and service registry. The structure is shown in Figure1. And the explanation of each element is as follows:

Service Provider: Also known as software providers. They provide services in the service registry, 
publish them to the service agent and respond the requests for the use of its service. The service providers of the platform include industrial cluster enterprises and service mediation.

Service Requester: They are the individual or organization who uses services, which look for and invoke other software services to provide business solutions. This platform of service requesters includes business users and individual users.

Service registry center: it is equivalent to a service information database, as the requestor and provider of an operational platform, to exchange information.

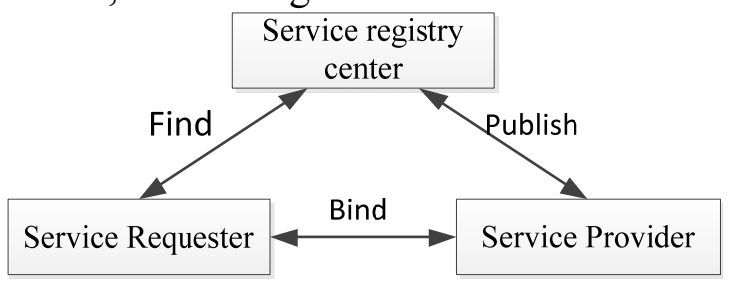

Figure1 Structure of SOA

The implementation of SOA also needs to understand the related technologies, such as: XML (an extensible representation language), Web services, BPEL (Business Process Execution Language), and so on.

XML: XML is a meta-markup language that supports user-defined markup language to describe and package the data in the file. Then, it is displayed in the browser by converting the file to HTML, etc. It realizes the data exchange between different applications and services through Interact, which has many characteristics, such as: heterogeneity, scalability, flexibility, self-describing nature as well as the integrity of the information. Above all, XML is very suitable for Web transmission

Web services: the Web service is a platform-independent, loosely coupled, self-contained, programmable Web-based application that can be used to describe, publish, discover, coordinate and configure these applications for the development of interoperable distributed applications by the opening XML standards.

BPEL: It is a markup language to describing a service combination, which merely develops a new type of business process definition language. Nevertheless, the concrete implementation process can be based on text specification to design their own graphical interface. Furthermore, it is used to define some process that can be executed by different platforms

\section{The Planning of the Technology Service Platform of Industry Cluster in Engineering Machinery Based on SOA}

The technology service platform of industry cluster in Engineering Machinery plays an important role in the perfection of engineering machinery industrial chain for the related businesses in Hunan Province, enhancing the cooperation among enterprises and research institutions. In the case of opening network, the platform uses the exchange of dynamic data and the sharing of network to achieve information synchronization of cooperation enterprise on the basis of the existing products of each enterprise and business information. Moreover, the platform develops a dynamic cooperative regulatory exchanging business information through business process execution language (BPEL) and the message system of Web, XML and service (Messaging Systems) [5], which is used as criteria to form a unified sharing center of data resource. At the same time, the platform straightens out the cross-business processes between collaborative enterprises to form an new mechanism of engineering machinery technology services under conditions of informationization across the enterprise.

Summary the Platform Requirements. Currently, the existing related companies of mechanical engineering basically have separate management systems and a series of service system with the characteristics of the enterprise itself, for example: public information management, test management, product development management, technology patents management. In most cases, the existing systems are independent development or implementation based on different platforms by individual enterprises, leading to the lack of coordination between related companies and no sharing in date to form an islands of information. Therefore, the technology service platform of 
industry cluster in Engineering Machinery provide multiple services for all kinds of companies, for example, applying for detection of the product, releasing information on technology transfer, contacting between enterprises collaborative research, publishing intellectual property information, applying for funding and answering questions of experts, and so on. Therefore, the platform fundamentally solves the dispersion, independence, redundancy and other shortcomings by integration of the original independent enterprises, to strengthen exchanges and cooperation between them.

Analyze the Functional of platform. After researching the demand of enterprises, we obtain the system level module of the technology service platform of industry cluster in Engineering Machinery, shown in figure 2. Platform portal is a core part of system that provides a SOA- based transparent and consistent information access and interoperability means for the service platform, including information integration, function integration, technology services business process, model integration and resource sharing.

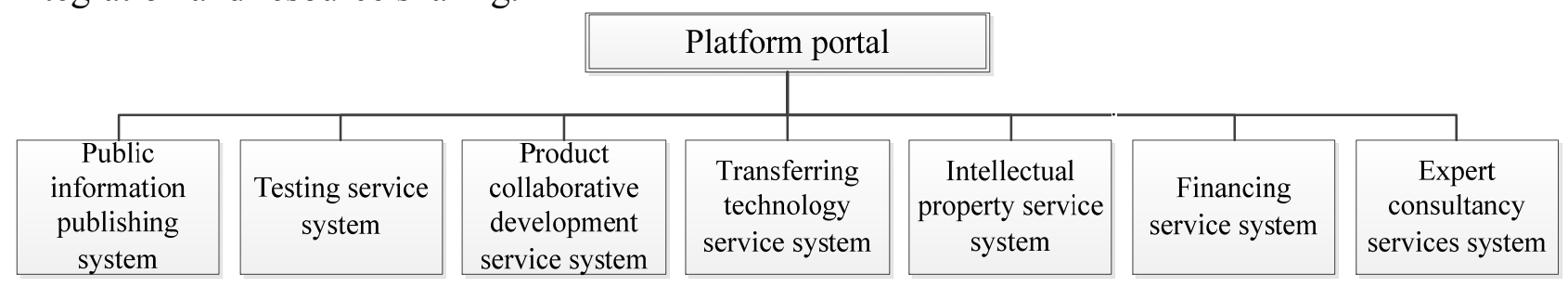

Figture2 Module chart of Technology Service Platform of Industry Clusters in Engineering Machinery

As it can be seen from the block diagram of system, the whole platform is mainly composed of the following aspects of the subsystem:

(1) Public information publishing system: For individual users, businesses and visitors, it shows public information related mechanical engineering, such as industry news, policies and regulations, and so on. Furthermore, it also shows the information, experts, and product information of relevant enterprises, which is obtained from its own information platform of various enterprise.

(2) Testing service system: The platform integrates various test \& research base of industry cluster in engineering machinery, including various key laboratories, engineering research centers and corporate $\mathrm{R} \& \mathrm{D}$ centers. Hence it is capable of organizing the advantage resource unit and establishing the resources sharing of detection of collaborative services alliance, which provides users with various cooperation unit testing instrument information and applications for all kinds of testing services.

(3) Product collaborative development service system: The platform can make full use of various resources of enterprises as the real support, such as the concentrated research and development personnel of the mechanical engineering, the related complete equipment and novelty searching in science and technology, and so on. In addition, the platform is applicable to service collaboration based on agile manufacturing engineering machinery and the product technology service collaboration among different enterprises or within an enterprise. Additionally, Users can publish content or application-related research studies in the system.

(4)Transferring technology service system: The enterprises, universities, research institutions and intermediary agency are integrated virtually in resources, personnel and service functions, which can provide users with the appropriate technical resources and publish information of transferring technology and Buying on the platform.

(5) Intellectual property service system: The platform is associated with intellectual property intermediary service and integrates the patents of enterprises of industry cluster in Engineering Machinery. Furthermore users can view and download the detailed information of the public patent and put forward patent application to agency services intermediary.

(6) Financing service system: The system can publish business credit information, financial information, credit guarantee information and company listing information, which make users publish and view various information in the interface.

(7) Expert consultancy services system: The platform integrates the information of well-known 
experts among enterprises, universities and scientific research institutions in engineering machinery, which provide users with expert information and send consultation information to experts.

The Overall Architecture of Integration Platform. According to the objectives and principles of system design, a schematic diagram of the overall architecture of the system is constructed by using of Web services-based SOA architecture, which as shown in Figure 3. The architecture is loosely coupled and distributed, which guarantees the system to be used between different companies and different users. What's more, the correlation system of the enterprise does not need to rewrite code because of SOA' characteristics of integrating existing applications, including internal information release system within every business, test management system, products management system as well as knowledge and technology management system. Therefore, the platform can publish the service to the integrated platform only by functional reuse.

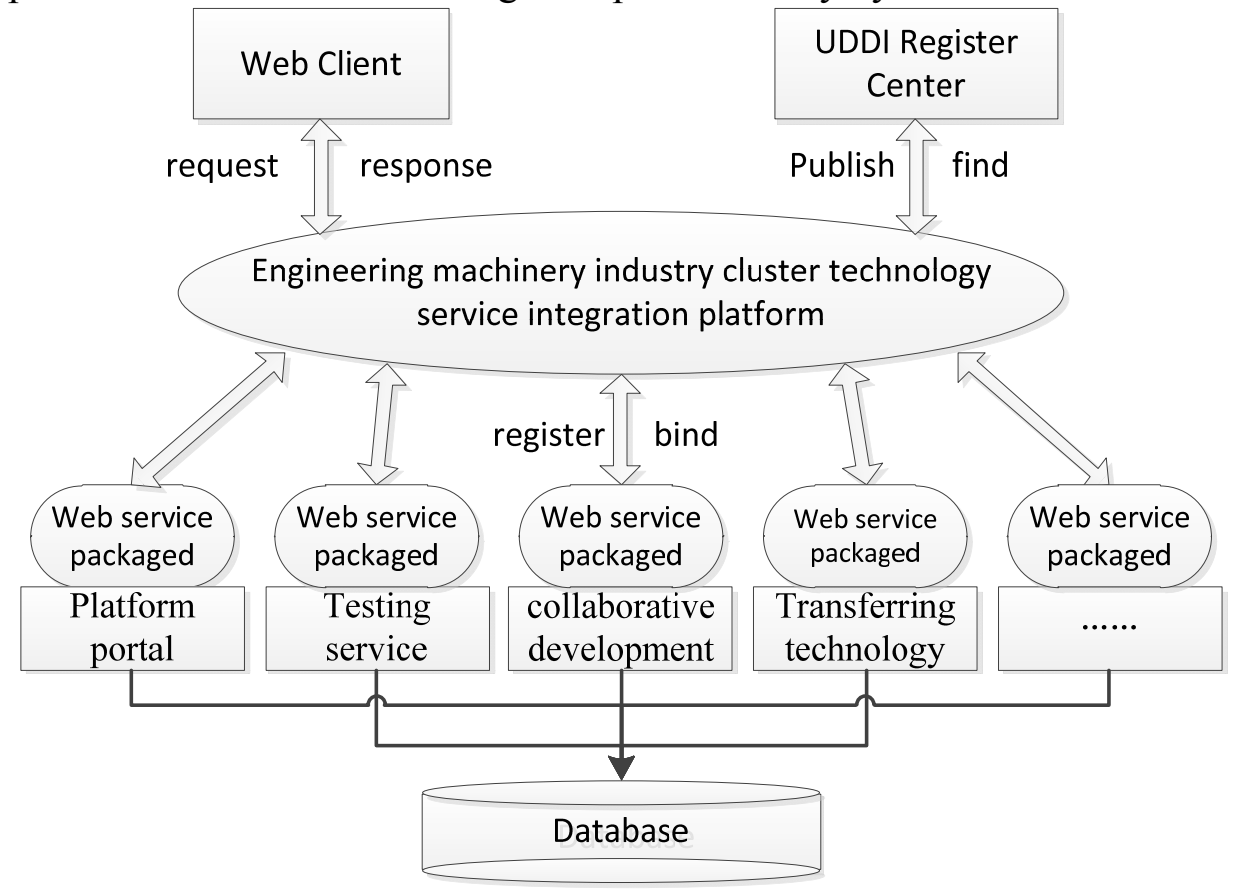

Figure3 Schematic diagram of the overall structure

On the basis of the architecture shown in figure 3 , the entire platform framework integration scheme is as follows:

(1) Firstly, the existing information within enterprises is analyzed and classified, including product information, test information, research and development information as well as related intellectual property right. Secondly, the public data of every enterprises are extracted and saved as the unified format. Lastly, the information mentioned above is organized into a global database.

(2) The function packages of each subsystem are sorted, which was packaged as a Web service.

(3) Based on the Internet, the technology service platform of industry cluster in Engineering Machinery is established, and then these Web services are connected to the platform. As a consequence, the each business system are able to interchange information through the Web service information, and simultaneously to ensure that they are independent of each other and stability are not affected.

Design the Experimental Testing Services Process. The detection system is a more complex sub-system of the whole platform, supplying a variety of service for the individual and enterprise users, such as viewing the test information, submitting an application, auditing and feedback. Besides, the specific links of the whole business process is a B2B service mode, providing a platform for users and the enterprises with offering test services to interact. To begin with, users submit the trial application according to their own need, and then the system sends the application to the relevant enterprises according to enterprise information. Lastly, the system gets a series of feedback through application integration between the detection system and each enterprise's own test information system.

The whole experiment processes in general are as follows: (1) Users (individuals or enterprises) 
submit a trial application through the detection system to enterprises provided test. (2) After getting the trial application in its own information system, each enterprise gives corresponding testing scheme and quotation and feedback to the platform of the detection system. (3) The system will send summary of each enterprise feedback information to the user for selection. (4) The system sends a notification to the enterprise information about arranging testing and reply the user test information. The entire process requires users to log into the portal of the technology service platform of industry cluster in Engineering Machinery, gaining access to detection system permissions before you can access to the test service system for trial application. Furthermore, the specific process was shown in figure $4(1)$.

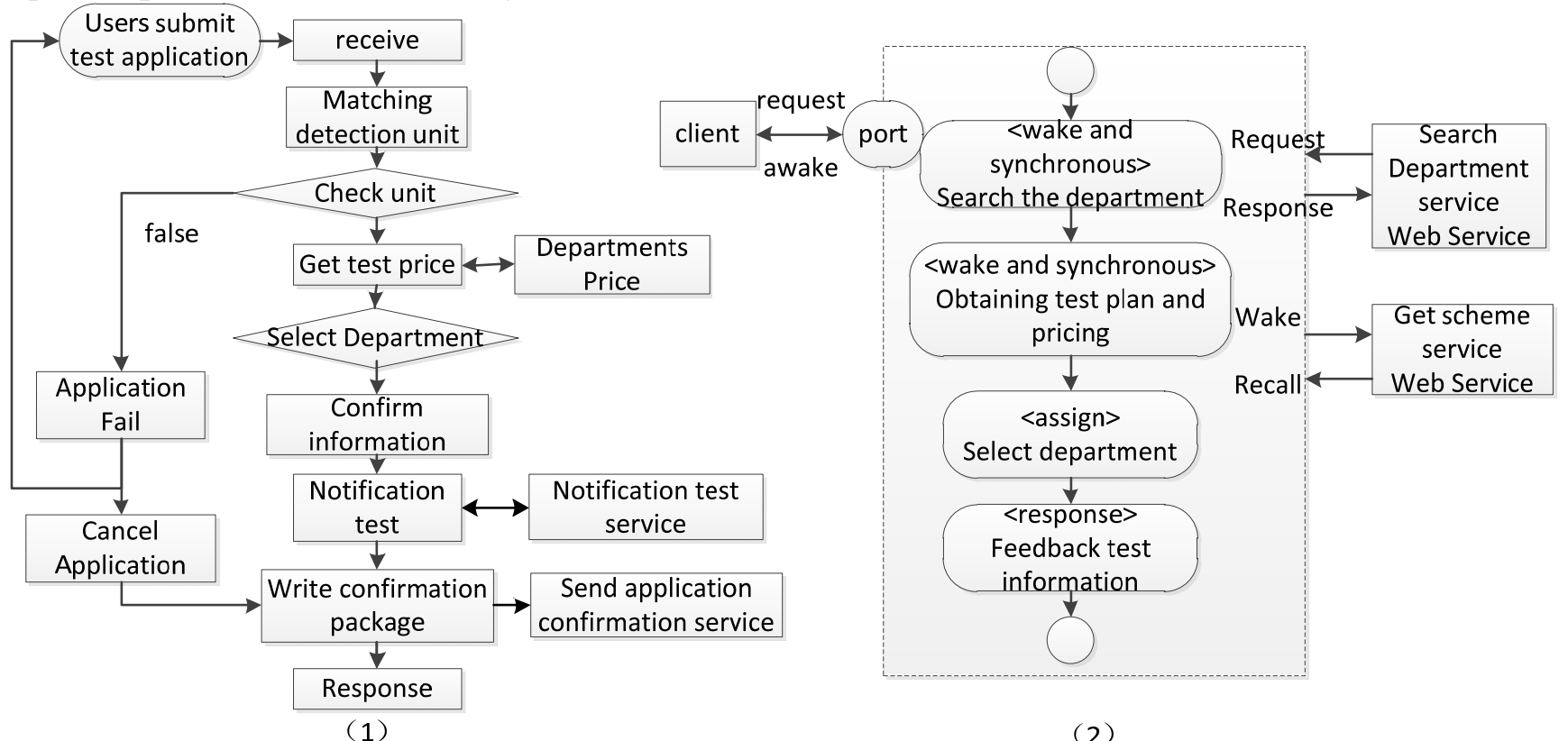

Figure 4 Test Application process and BPEL process

The above processes is simplified as BPEL model, as shown in Figure 4(2) Then, this series of Web services is further deployed to the environment of Oracle BPEL Process Manager for testing. And then Oracle works out the details of the BPEL through an XML file, including BPEL source file name, the BPEL process ID, WSDL locations and optional configuration properties of all partner link WSDL Web services. After testing, the whole process showed good operational status and fast response, hence the rest of the sub-service processes are designed by BPEL models.

\section{Summary}

The technology service platform of industry cluster in Engineering Machinery can't respond quickly to changes, causing an adverse impact on the flow and processing of a large number of information, which is attributed to wasting resources for its massive and too dispersed information. In this paper, the SOA-architecture-based was adopted, which integrates the large amounts of data information dispersed over various companies, responding more quickly and effectively. The trail application service was taken as an example to describe the design and testing of the specific process. In addition, the system running result shows that the SOA-construction-based technology service platform has a loose coupling, fast response, high treatment efficiency and good scalability, which not only improves greatly the efficiency of the system, but also promotes the mutual exchanges and resources integration and sharing between each enterprise in industrial cluster. Meanwhile, the development of the platform provides a reference for the improvement of the future platform functions and the technology service of industry cluster in Engineering Machinery. 


\section{Acknowledgement}

In this paper, the work was sponsored by the National Science and Technology Support Program of China (No. 2012BAH11F01) and the Hunan Soft Science Research Program of China (No. 2013ZK3026).

\section{References}

[1] Yang Shuigen: The Internal Mechanism Among Industrial Chain, Industrial Clusterand Industry Cluster Competitiveness, Vol.27 (2011),P.50.-55.

[2] Ling Xiaodong: Areview of SOA, Computer Applications ans software, Vol.24(2007),P.122-124+199.

[3] Chen Yuming: Platform for Cigarettemarket Supervision and Information Sharing Based on SOA, Computer Systems \& Applications, Vol.25(2015),P.80-84

[4] Mark Scardina, Ben Chang, Jinyu Wang: Oracle Database 10g \&SQL XML: Design, Build \&Manage XML Applications in Java,C,C++ \&PL/SQL. (Tsinghua University Publications, China 2006).

[5] Wu Jiaju, Liu Gang, Xi Chuanyu: Study on Service Oriented Architecture Based of Web Service, Modern Electronic Technique, Vol.14(2005),P.1-3+7

[6] Zhang Haifeng, Ma su Soa-Based Enterprise Application Intergration Technology Research and Iimplementation, Computer Systems \& Applications, Vol.28(2011),P192-194.

[7] Li Songhua,Tao Lihong, Gao Dong: Research and implementation of related technology for a logistics information sys-tem based on SOA, Journal of University of Science and Technology Beijing, Vol.31(2009),P.134-138. 